\title{
O uso de fitoterápicos à base de aroeira como coadjuvante no tratamento da gengivite: Revisão Sistemática
}

DIAS, J.N. ${ }^{*} ;$ SILVA, M.P.C.F. ${ }^{1 ;}$ LIMA, I.P.C. ${ }^{1}$

1Universidade do Estado do Rio Grande do Norte, Campus Caicó. Rua André Sales, 667, Paulo XI, CEP: 59300-

000, Caicó-RN. *Autor para correspondência: josynobrega14@gmail.com

RESUMO: O fator mais importante na manutenção da saúde periodontal é o adequado controle do biofilme dentário. Face às dificuldades no controle mecânico por parte dos pacientes, métodos alternativos ou complementares têm sido utilizados como coadjuvantes químicos do controle do biofilme, auxiliando no tratamento da gengivite. Dentre esses métodos alternativos, destaca-se a fitoterapia, através da utilização de plantas medicinais. Dessa forma, esse estudo faz uma revisão sistemática tendo como objetivo a busca, na literatura atual, de estudos que comprovem a eficácia de produtos fitoterápicos à base de aroeira no controle do biofilme dental auxiliando no tratamento da gengivite. Foi realizada busca computadorizada nos indexadores MedLine, Lilacs, BBO e Scielo no período de Setembro a Outubro de 2014. Os descritores de pesquisa utilizados foram "biofilme", "gengivite", "aroeira", "plantas medicinais" e "fitoterápicos", bem como seus correspondentes em língua inglesa. Através dos descritores utilizados, foram encontrados 54 artigos. Após a aplicação dos critérios de inclusão e exclusão, chegou-se a 08 artigos: 05 revisões, 01 estudo clínico randomizado, 01 estudo experimental e 01 estudo observacional descritivo. De acordo com os estudos analisados, a aroeira apresentou atividades antifúngica e antimicrobiana eficazes, bem como potencial efeito de redução do índice de sangramento gengival, o que justifica seu uso no tratamento da gengivite.

Palavras-chave: aroeira, gengivite, plantas medicinais.

\begin{abstract}
The use of aroreira-based phytotherapics as a supporting tool in the treatment of gingivits: A systematic Review.The most important factor to keep periodontal health is proper control of biofilm. Given the difficulties in the mechanical control by patients, alternative or complementary methods have been used as chemical supporting of biofilm control, helping the treatment of gingivitis. Among these alternatives, there is the phytotherapy, through the use of medicinal plants. Thus, this study it is a systematic review and aims to seek, in the current literature, researches proving the effectiveness of aroeira herbal products in the control of dental biofilm, assisting in the treatment of gingivitis. A computerized search was conducted in Medline, Lilacs, Scielo and BBO, from September to October of 2014. The search words used were "biofilm", "gingivitis", "aroeira", "herbal medicines" and "phytotherapics" in Portuguese and English language. Through this method, 54 articles were found. After applying the inclusion and exclusion criteria, the research reached 08 items: 05 reviews, 01 randomized clinical trial, 01 experimental study and 01 descriptive observational study. According to the analyzed papers, the aroeira demonstrated effective antifungal and antimicrobial activities, as well as a potential reduction impact on gingival bleeding index, which would justify its use in the treatment of gingivitis.
\end{abstract}

Keywords:aroeira, gingivits, herbal medicines.

\section{INTRODUÇÃO}

A formação do biofilme dentário é o fator desencadeante dos processos patológicos que acometem a estrutura do elemento dental e o tecido de suporte dentário, assim o controle mecânico do biofilme é imprescindível quando se quer controlar o desenvolvimento de doenças como cárie,gengivite e periodontite (Juiz et al., 2010).

A gengivite é uma das doenças periodontais 
mais freqüentes, afetando mais de $90 \%$ da população, independentemente da idade, sexo ou raça (Villaloboset al., 2001). Por isso torna-se importante o desenvolvimento de estudos que comprovem a eficácia de substâncias químicas, em especial os fitoterápicos, os quais devem atuar como coadjuvantes no controle de placa, que muita vezes é negligenciado pelo paciente.

A utilização crescente da fitoterapia entre os programas preventivos e curativos tem estimulado o estudo dos extratos de plantas para o uso na odontologia como controle do biofilme dental e outras afecções bucais, aumentando as pesquisas com produtos naturais no meio odontológico nos últimos anos devido à busca por novos produtos com maior atividade terapêutica, com menor toxicidade e melhor biocompatibilidade, além de apresentarem custos mais acessíveis à população (Francisco, 2010).

O fitoterápico atua como uma substância adjuvante adicionada ao medicamento com a finalidade de prevenir alterações e corrigir e/ ou melhorar as características organolépticas, biofarmacotécnicas e tecnológicas desse medicamento (Lima Júnior, 2005).

Diversos produtos de origem vegetal mostram ser potencialmente interessantes, no que se refere a sua atividade antimicrobiana. Dentre esses produtos, destaca-se a aroeiraque é mais estudada nas espécies (Schinusterebinthifolius) e (Myracrodruonurundeuva), nas suas diversas formas de preparo.

A aroeira possui ação antimicrobiana, antiinflamatória e antiulcerogênica, sendo utilizada como antisséptico e no tratamento de estomatites. Além disso, apresenta atividade bactericida e bacteriostática sobre Streptococusmutans, Streptococusmitis, Streptococussobrinus, Streptococussanguis, Lactobacillus casei e ação antifúngica sobre Cândida albicans, Cândida tropicalis e Cândida krusei (Brandãoet al., 2006).

A busca por produtos naturais com atividade antibacteriana no combate a doenças que afetam o elemento dental tem merecido destaque, principalmente com o advento de cepas multirresistentes a antibióticos (Roberts, 2002), bem como os efeitos colaterais associados ao uso da clorexidina, que é considerada como padrão ouro no controle da placa bacteriana (Jones, 1997).

Dessa forma, numerosos produtos com ingredientes de origem vegetal estão sendo cada vez mais testados por exercer influência inibitória no crescimento do biofilme dentário na cavidade oral (Lima Júnior, 2005).

Assim, torna-se necessário pesquisar sobre o uso de fitoterápicos à base de aroeira no tratamento da gengivite, com o intuito de incentivar novos estudos, envolvendo seres humanos, para que assim seja possível conhecer os verdadeiros efeitos clínicos desta planta medicinal e desenvolver fitoterápicos eficazes e seguros.

Com isso, o objetivo desta revisão sistemática é buscar, na literatura atual, estudos que comprovem a eficácia de produtos fitoterápicos à base de aroeira no controle do biofilme dental, auxiliando no tratamento da gengivite.

\section{MATERIAL E MÉTODO}

Foi realizada uma busca computadorizada nos indexadores MedLine, Lilacs, BBO e Scielo,no período de Setembro a Outubro de 2014. Os descritores de pesquisa utilizados foram "biofilme", "gengivite", "aroeira", "plantas medicinais" e "fitoterápicos", bem como seus correspondentes em língua inglesa.A lista inicial de artigos foi submetida a análise por dois avaliadores, que aplicaram critérios de inclusão e exclusão para determinar a amostra final de artigos, que foram avaliados pelo seu título e resumo. Foram utilizados os seguintes critérios de inclusão para a seleção dos artigos: Estudos que relacionassem a fitoterapia com a gengivite, Estudos clínicos randomizados (RCTs), Estudos clínicos longitudinais prospectivos não randomizados, revisões sistemáticas e meta-análises, sendo que os estudos clínicos deveriam apresentar grupo controle. Foram excluídos estudos publicados antes de 2004, relatos de caso clínicoe opiniões de autores, Estudos experimentais com animais, além de estudos onde o tratamento ainda não tivesse sido concluído.

\section{RESULTADOS}

Através dos descritores utilizados, foram encontrados 54 artigos. Após a aplicação dos critérios de inclusão e exclusão, chegou-se a 08 artigos: 05 revisões, 01 estudo clínico randomizado, 01estudo experimental e 01 estudo observacional descritivo, conforme demonstra a Figura 1. A amostra final de artigos selecionados foi dividida em dois grupos (Tabelas1 e 2)1.estudos clínico, experimental e observacionale 2.revisões.

\section{DISCUSSÃO}

$\mathrm{Na}$ Odontologia, assim como nas demais áreas da Saúde, várias pesquisas são realizadas com intuito de solucionar as patologias e de melhorar as condições de vida do paciente. Desta forma, estudos visam descobrir novas alternativas e/ou materiais que ofereçam melhores condições e menores custos aos pacientes (Francisco, 2010).

De acordo com Juiz et al. (2010), a

Rev. Bras. PI. Med., Campinas, v.17, n.4, supl. III, p.1187-1191, 2015. 


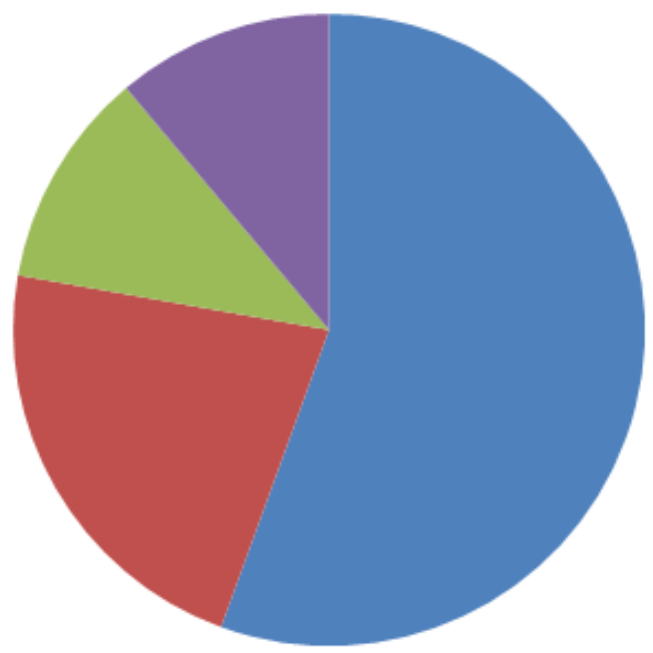

Revisões

Estudo experimental

Estudo clínico randomizado

Estudo observacional descritivo

FIGURA 1. Delineamento dos Estudos

TABELA 1. Delineamento dos Estudos

\begin{tabular}{|c|c|c|c|c|}
\hline Autores & $\begin{array}{c}\text { Ano de } \\
\text { publicação }\end{array}$ & Desenho & $\begin{array}{c}\text { Tamanho da } \\
\text { amostra }\end{array}$ & $\begin{array}{c}\text { O estudo relaciona o uso da } \\
\text { aroeira com o tratamento da } \\
\text { gengivite? }\end{array}$ \\
\hline Lima Júnior et al. & 2005 & Estudo Observacional Descritivo & 212 domicílios & SIM \\
\hline Alveset al. & 2009 & Estudo experimental & $\begin{array}{l}5 \text { linhagens } \\
\text { bacterianas }\end{array}$ & SIM \\
\hline Linset al. & 2013 & RCT duplo-cego & 59 pacientes & SIM \\
\hline
\end{tabular}

TABELA 2. Revisões

\begin{tabular}{|c|c|c|c|c|}
\hline Autores & $\begin{array}{l}\text { Ano de } \\
\text { publicação }\end{array}$ & Desenho & $\begin{array}{l}\text { O estudo relaciona o uso de } \\
\text { Fitoterápicos com o tratamento } \\
\text { de lesões bucais? }\end{array}$ & $\begin{array}{l}\text { O estudo relaciona o } \\
\text { uso da aroeira com o } \\
\text { tratamento da gengivite? }\end{array}$ \\
\hline Borghiet al. & 2005 & Revisão & SIM & $\mathrm{NA \tilde {O }}$ \\
\hline Francisco & 2010 & Revisão & SIM & SIM \\
\hline Juiz et al. & 2010 & Revisão & SIM & NÃO \\
\hline Catãoet al. & 2012 & Revisão Sistemática & SIM & NÃO \\
\hline Machado\&Oliveira & 2014 & Revisão & SIM & NÃO \\
\hline
\end{tabular}

terapia periodontal convencional realizada com sucesso tem o objetivo de manter a saúde dos tecidos periodontais, porém a recolonização da área subgengival pelos periodontopatógenos, resultado de uma terapia preventiva de manutenção falha, pode acarretar em uma doença recorrente. Desta forma produtos naturais poderiam auxiliar no controle do crescimento do biofilme dental subgengival, essencial para a manutenção dos tecidos periodontais.

As plantas medicinais constituem um importante recurso terapêutico para o tratamento da saúde. A abrangência da utilização de fitoterápicos é vasta e engloba fins variados, sobretudo em relação à saúde bucal (Linset al., 2013).A Fitoterapia faz parte do Sistema Único de Saúde, sendo possível a sua inclusão médica e odontológica (Brasil, 2006).

Para Catão et al. (2012), os produtos fitoterápicos possuem, na maioria das vezes, ação mais suave que os medicamentos alopáticos, visto que o princípio ativo da planta não é utilizado de maneira isolada, atuando juntamente com outras substâncias presentes nas plantas, resultando em efeitos colaterais reduzidos o que justifica seu uso em substituição aos medicamentos convencionais. Em estudo realizado por Lima Júnior et al. 
(2005), o qual buscou investigar o uso de plantas medicinais na população para tratar infecções bucais através da aplicação de questionários, a aroeira foi apontada como útil para o tratamento da inflamação gengival, sendo citada por $41 \%$ das pessoas entrevistadas.

Com relação ao estudo experimental realizado por Alves et al. (2009), o qual avaliou o extrato hidroalcoólicoin vitro da aroeira-do-sertão (Myracrodruonurundeuva), foi observado que esta apresentou atividade bactericida e bacteriostática sobre S. mutans, S. mitis, S. sobrinus, S. sanguis e L. casei, como também ação antifúngica sobre C. albicans, C. tropicalis e C. krusei. Além disso, verificou a capacidade da aroeira em inibir a síntese do glucano pela glicosiltransferase, por meio de sua ação antiaderente in vitro, semelhante à clorexidina $0,12 \%$.

No estudo clínico randomizado duplocego feito por Lins et al. (2013), o qual objetivou avaliar clinicamente o efeito de bochechos à base de extratos das plantas medicinais, aroeira (Schinusterebinthifolius) e camomila (Matricariarecutita L.), sobre o controle da placa bacteriana e o tratamento da gengivite, através dos índices de placa e de sangramento gengival, o grupo com bochecho de Aroeira apresentou menores índices de sangramento quando comparado ao bochecho com Clorexidina e com Camomila.A avaliação da redução do índice de placa ao longo dos três momentos (inicial, após 7 e 15 dias), nos 3 grupos (Clorexidina, Camomila e Aroeira) foi realizada separadamente e os resultados apontaram que os índices de placa apresentaram uma redução significativa nos três grupos distintos.

Em sua revisão, Francisco (2010) encontrou que a aroeira (Schinusterebinthifolius) possui ação antimicrobiana, anti-inflamatória e antiulcerogênica, sendo utilizada como antisséptico e no tratamento de estomatites. Além disso, apresenta atividade bactericida e bacteriostática sobre Streptococusmutans, Streptococusmitis, Streptococussobrinus, Streptococussanguis, Lactobacillus casei. Constatou também a capacidade de inibir o crescimento bacteriano de diversos extratos vegetais aquosos e hidroalcoólicos, dentre estes o da folha da aroeira-do-sertão (Myracrodruonurundeuva).

Machado \& Oliveira (2014) observaram em seu estudo sobre a aroeira-do-sertão (Myracrodruonurundeuva), que esta planta é muito utilizada pela população do nordeste do Brasil para vários tipos de infecções em geral, dor de cabeça, dor de dente, antisséptico, inflamação em geral, etc. De acordo com diversos estudos avaliados pelos autores, a aroeira apresentou potente atividade antimicrobiana, antifúngica e antiulcerogênica.

Borghiet al. (2005) observaram em seu estudo sobre métodos alternativos para tratamento de afecções bucais, que uma das plantas utilizadas pela população devido a sua ação anti-inflamatória é a aroeira.

Certamente, a propriedade mais estudada do extrato de aroeira até o presente momento é o efeito antimicrobiano. Diversos trabalhos na literatura tem testado o extrato da aroeira, o qual tem mostrado bons resultados em pesquisas envolvendo o controle de microrganismos relacionados à patologias bucais.

De acordo com os estudos analisados, a aroeira apresentou atividades antifúngica e antimicrobiana eficazes, bem como potencial efeito de redução do índice de sangramento gengival, o que justifica seu uso no tratamento da gengivite.

\section{REFERÊNCIAS}

ALVES, P.M. et al.Atividade antimicrobiana, antiaderente e antifúngica in vitro de plantas medicinais brasileiras sobre microrganismos do biofilme dental e cepas do gênero Candida. Revista da Sociedade Brasileira de Medicina Tropical, v.42, n.2, p.222-224, 2009.

BORGHI, W.M.M.C. et al. Métodos Alternativos para higienização bucal e terapêutica odontológica, Revista do Instituto de Ciências da Saúde, v.23, n.4, p.309314, 2005.

BRANDÃO, E.H.S. et al. Antimicrobial activity of coffeebased solutions and their effects on Streptococcus mutans adherence. BrazilianJournalof Oral Science, v.6, n.20, p.1274-1277, 2006.

BRASIL, Ministério da Saúde. Secretaria de Atenção à Saúde. Política Nacional de Práticas Integrativas e Complementares no SUS. Brasília: Editora MS, 2006. 92p.

CATÃO, M. H. C. V. et al. Estudos Clínicos com Plantas Medicinais no Tratamento de Afecções Bucais: Uma Revisão de Literatura.Unopar Científica Ciências Biológicas e da Saúde, v.14, n.4, p.279-285, 2012.

FRANCISCO, K. S. F. Fitoterapia: uma opção para o tratamento odontológico. RevistaSaúde, v.4, n.1, p.1824, 2010.

JONES, C.G. Chlorhexidine: is it still the gold standart? Periodontol 2000, v. 15, p. 55-62, 1997.

JUIZ, P. J. L.et al. Uso de produtos naturais como coadjuvante no tratamento da doença periodontal. Revista Brasileira de Farmacognosia, v. 20, n.1, p.134-139, 2010.

LIMA JÚNIOR, J. F. et al. O Uso de Fitoterápicos e a Saúde Bucal. Saúde em Revista, v.7, n.16, p.11-17, 2005.

LINS, R. et al., Avaliação clínica de bochechos com extratos de Aroeira (Schinusterebinthifolius) e Camomila (Matricariarecutita L.) sobre a placa bacteriana e a gengivite.Revista Brasileira de Plantas Medicinais, v.15, n.1, p.112-120, 2013.

MACHADO, A.C.; OLIVEIRA, R.C. Medicamentos Fitoterápicos na odontologia: evidências e

Rev. Bras. PI. Med., Campinas, v.17, n.4, supl. III, p.1187-1191, 2015. 
perspectivas sobre o uso da aroeira-do-sertão (MyracrodruonurundeuvaAllemão).Revista Brasileira de Plantas Medicinais, v.16, n.2, p.283-289, 2014.

ROBERTS, M.C. Antibiotic toxicity, interactions and resistence development.Periodontol 2000, v.28, p.
280-297, 2002.

VILLALOBOS, O.J. et al. Efecto de unenjuague bucal compuesto de aloe vera em la placa bacteriana e inflamacióngingival. Acta OdontologicaVenezolana, v.39, n.2,p.16-24, 2001.

Rev. Bras. PI. Med., Campinas, v.17, n.4, supl. III, p.1187-1191, 2015. 